\title{
DOSSIÊ BAUDELAIRE: O ENCONTRO DA POÉTICA DE BENVENISTE COM A POÉTICA DE MESCHONNIC
}

\section{BAUDELAIRE'S DOSSIER: BENVENISTE AND MESCHONNIC'S POETIC CONVERGENCE}

\author{
Daiane Neumann ${ }^{1}$ \\ Universidade Federal de Pelotas, UFPel, Pelotas, RS, Brasil
}

\begin{abstract}
Resumo: Neste artigo, proponho-me a refletir acerca da relação entre a poética de Émile Benveniste, no que tange ao dossiê Baudelaire, publicado em 2011, na França, e a poética de Henri Meschonnic, cuja obra inicia em finais da década de 50. Para fazê-lo, considero a discussão proposta por Benveniste em PLG I e II, que importa à literatura, a fim de discutir acerca da reflexão que concerne à "linguagem poética", proposta em Baudelaire. Por fim, é de meu interesse chegar a consideraçôes sobre o encontro da poética de Benveniste com a poética de Meschonnic, via análise de texto literário.
\end{abstract}

Palavras-chave: Baudelaire; poética; Benveniste; Meschonnic.

Abstract: Émile Benveniste's Poetic in Baudelaire's dossier, released in France, 2011, has presented a core relation to Henri Meschonnic's Poetic from the late 1950's. This paper aims at discussing this topic and, therefore, firstly Benveniste's ideas in Problems in General Linguistics I and $I I$ concerning Literature have been addressed; secondly, Baudelaire's reflections concerning "Poetic Language" have been discussed as well. Finally, Benveniste and Meschonnic's Poetic convergence has been discussed through literary texts analysis since this research has been delevoped via Literature.

Keywords: Baudelaire; poetic; Benveniste; Meschonnic.

\section{Introduçáo}

Em entrevista a Chloé Laplantine, Flores e Teixeira (2013, p. 223) afirmam que "a divulgação do livro Baudelaire e mais recentemente de Dernières leçons tem provocado quase que uma 'revoluçáo' nos estudos

1Professora dos cursos de Letras e do Programa de Pós-Graduação em Letras da Universidade Federal de Pelotas. Doutora em Estudos da Linguagem pela Universidade Federal do Rio Grande do Sul. E-mail para contato: daiane_neumann@hotmail.com 
benvenistianos". Considerando a afirmação proposta pelos dois estudiosos da obra de Benveniste, proponho-me a focar o debate, neste artigo, em torno da primeira publicação dessa "revolução", qual seja, a do dossiê Baudelaire.

A publicação dessa obra, em 2011, trouxe novas reflexóes e apontou caminhos de trabalho para aqueles pesquisadores que se dedicaram a estudar, propriamente, a relação entre Benveniste e a literatura. Na França, esse movimento deu-se em torno dos trabalhos ${ }^{2}$ desenvolvidos a partir da poética de Meschonnic, que tem como um de seus linguistas de base Benveniste. No Brasil, o movimento deu-se a partir de trabalhos ${ }^{3}$ produzidos na UNISINOS, orientados pela professora e pesquisadora Marlene Teixeira, "leitora maior" $\mathrm{da}$ obra de Benveniste.

O trabalho de leitura e organização dos manuscritos, por Chloé Laplantine, culminou em uma tese de doutoramento, defendida em 2008, Émile Benveniste : poétique de la théorie. A publicação dos manuscritos, em 2011, gerou mais algumas produçóes, na França, em torno da obra, Émile Benveniste, pour vivre langages, Des notes manuscrites de Benveniste sur la langue de Baudelaire ${ }^{6}$, Émile Benveniste: vers une poétique générale 7 . No Brasil, testemunhamos também a produção de alguns trabalhos, como a tese de doutoramento de Sabrina Vier, Quando a linguistica encontra a linguagem: da escrita de Émile Benveniste presente no Dossiê Baudelaire ao estudo semiológico de uma obra literária, e produçóes que decorreram de seu trabalho de tese.

Considerando esse contexto de produção, é de meu interesse, neste artigo, discutir, em um primeiro momento, sobre essa reflexão proposta na obra de Benveniste, que interessa à literatura, no sentido de que traz contribuiçōes para compreender, propriamente, o literário, o poema ${ }^{8}$,

${ }^{2}$ Dentre esses trabalhos, estão aqueles desenvolvidos por Gérard Dessons, Serge Martin e Chloé Laplantine.

${ }^{3}$ Remeto, aqui, aos trabalhos de mestrado de Juciane dos Santos Cavalheiro, O espaço ficcional e a experiência subjetiva: uma análise enunciativa de A Metamorfose, de Sabrina Vier, Da singularidade nalda linguagem poética: um estudo enunciativo em cançôes de Chico Buarque, e de Luana Müller de Mello, Em busca da representação de trabalhador em cançôes de Chico Buarque: um estudo enunciativo da linguagem poética.

${ }^{4}$ FLORES, V. do N., e NEUMANN, D. Apresentação do Dossiê Leituras de Émile Benveniste. Revista Linguagem \& Ensino. v. 23, n. 3, julho-setembro, 2020.

${ }^{5}$ MARTIN, Serge (Org.) (2009).

${ }^{6}$ ADAM, Jean-Michel e LAPLANTINE, Chloé (Org.) (2012).

7BÉDOURET-LARRABURU, Sandrine e LAPLANTINE, Chloé (Org.) (2015).

${ }^{8}$ Para Dessons (2011), o poema náo deve ser necessariamente escrito em verso, pois mesmo que 
conforme o denominam Henri Meschonnic e Gérard Dessons. Em um segundo momento, busco problematizar o encontro da poética de Benveniste com a poética de Meschonnic, a partir do dossiê Baudelaire, isto é, a partir da consideraçáo do texto literário, a fim de levantar problematizaçóes que concernem não somente aos que se dedicam a pesquisas acerca do trabalho desses dois estudiosos, mas também aos que se interessam pela discussão acerca da constituição do texto literário.

\section{A arte e a literatura: dos PLG I e $I I$ ao dossiê Baudelaire}

Em entrevista intitulada Émile Benveniste e a arte de pensar: uma entrevista com Gérard Dessons ${ }^{2}$, o teórico da linguagem afirma que, com o movimento do "linguistic turn", as ciências humanas situam a linguagem na vanguarda de seus objetos de estudo. Dessa forma, a literatura vai se encontrar em um verdadeiro problema, na medida em que é tratada à parte, como anticiência. A separaçáo do que Dessons denominou "poema" e "língua" levará a uma "verdadeira dificuldade", "de um lado, os departamentos de literatura trabalhando sobre o plano do significado; de outro, os departamentos de linguística ('ciências da linguagem') ocupandose antes do significante" (DESSONS; NEUMANN; OLIVEIRA; 2020, p. 375).

Ora, uma leitura atenta dos PLG I e II mostra, como bem apontaram Messa e Teixeira (2015), que o ponto de convergência da multiplicidade de interesses do universo benvenistiano está na questáo da significação. A questão da significação, em Benveniste, é atravessada pela reflexão acerca do que chamou, em A forma e o sentido na linguagem, de "noçóes gêmeas de sentido e de forma" (BENVENISTE 2006a, p. 221). Benveniste, o mais saussuriano dos linguistas do discurso, não fez a separação entre o plano do significante e o plano do significado, nem em sua reflexão que retoma a proposta saussuriana, por ele denominada domínio semiótico, nem mesmo quando abre suas proposiçôes teóricas ao domínio do semântico, ou seja, ao domínio do discurso. Ademais, ao investigar questóes de forma, sem desconsiderar o sentido, a significação, Benveniste é levado a tratar da questão da subjetividade na linguagem, da relação da língua com a cultura,

o verso tenha sido historicamente a forma do poema, durante muitos séculos, ele não o é mais desde que a ideia de poesia foi alterada no século XVII, quando houve a versificação da prosa, o que resultou no século XIX no poema em prosa.

${ }^{9}$ Dessons, Neumann, Oliveira (2020). 
da língua com a sociedade, da língua com o pensamento. Assim, estabeleceu uma reflexão sobre a linguagem que se constituiu no que mais tarde foi denominado, por Henri Meschonnic e Gérard Dessons, de uma "teoria do conjunto".

Tal constatação permite compreender por que ao escrever sobre a obra de Émile Benveniste, Henri Meschonnic intitulou um de seus textos "Seul comme Benveniste"10. Da mesma forma, Gérard Dessons (2006, p. 16) afirma que Benveniste "é um linguista à parte". Ademais, essa teorização particular de Benveniste, muito caracterizada por uma preocupação com a significação, chamou a atenção de outros estudiosos da literatura, como Roland Barthes e Tzvetan Todorov, notadamente leitores da obra benvenistiana.

Estudiosos da literatura perceberam, desde muito cedo, que a linguística benvenistiana lançava luzes sobre problemas com que se deparavam em análises de textos literários. De forma geral, podemos apontar como propulsora desse interesse a questáo que mobilizou esse linguista inquieto do início ao fim de sua teorização, a questáo da significação; "o que não se tentou para evitar, ignorar ou expulsar o sentido? É inútil: essa cabeça de Medusa está sempre aí, no centro da língua, fascinando os que a contemplam" (BENVENISTE, 2005a, p. 134-135).

Vier (2016) faz um levantamento de como a literatura comparece nos PLG I e II. A autora mostra a presença da literatura através de excertos de textos, em análises operadas por Benveniste, bem como em citaçóes e em algumas mençôes feitas à literatura em alguns capítulos. Desse universo de possibilidades, discuto aqui, por observar que se trata de questóes que dialogam de forma estreita com aquelas levantas por Benveniste no dossiê Baudelaire, acerca do texto "Observaçóes da função da linguagem na descoberta freudiana" e "Semiologia da língua".

No texto "Observaçōes da função da linguagem na descoberta freudiana”, publicado originalmente em 1956, Benveniste (2005b, p. 90), considerando a tentativa freudiana de encontrar um discurso análogo à linguagem do inconsciente e dos sonhos, com o objetivo de compreendêlos, observa que o que "Freud perguntou em vão à linguagem 'histórica' teria podido, em certa medida, perguntar ao mito ou à poesia”.

Tal observação é feita após uma tentativa de Benveniste de caracterizar a linguagem do inconsciente. Para o linguista sírio (2005b), além do simbolismo inerente à linguagem, o analista percebe que há um simbolismo 
específico, que se constitui tanto a partir do que o sujeito omite quanto a partir do que enuncia, sem conhecê-lo. Ademais, Benveniste (2005b, p. 85) percebe que Freud "lançou luzes decisivas sobre a atividade verbal tal como se revela na suas fraquezas, nos seus aspectos de jogo, na sua livre divagação quando se suspende o poder de censura", portanto, "toda a força anárquica que refreia ou sublima a linguagem normalizada, tem a sua origem no inconsciente".

O psicanalista, de acordo com Benveniste (2005b, p. 85), observou a existência de "profunda afinidade entre essas formas da linguagem e a natureza das associaçóes que se estabelecem no sonho - outra expressão das motivações inconscientes". Dando seguimento à sua reflexão, Benveniste lança mão das palavras de Freud, para quem "essa linguagem simbólica" "não é específica do sonho; encontramo-la em toda a imagística inconsciente, em todas as representaçóes coletivas, principalmente populares: no folclore, nos mitos, nas lendas, nos ditados, nos provérbios, nos trocadilhos correntes; ela é, mesmo, mais completa aí que no sonho" (BENVENISTE, 2005b, p. 93).

Nas notas manuscritas, Benveniste (2011) insiste, em diversos momentos, sobre o fato de que "o referido <em poesia> não é o mundo das / coisas, é o mundo interior do poeta, ou [...] é / o mundo das coisas refratadas na consciência do poeta, <quer / dizer uma experiência>"1112 (p. 130). Observando propriamente a "língua de Baudelaire", o linguista observa que Baudelaire é o poeta da interioridade do ser, da verdade profunda dos sofrimentos do homem na natureza. Esse estilo descreve "as aspiraçóes, os / delírios, as lembranças no / estilo que convém à exte/ rioridade"13 (p. 418).

No entanto, esse "mundo interior do poeta", de que fala Benveniste (2011), começa a se tornar um "mundo/ segundo", um "mundo da / sensibilidade tomado nele mesmo", o "mundo do sonho e da nostalgia"14 (p. 418). A descrição, em Baudelaire, conforme observa Benveniste, vem "o sonho, tem cores oníricas"15 (p. 426). É importante perceber o quanto

\footnotetext{
11 Tradução minha. No original, lê-se: "Le référé <en poésie> n'est pas le monde des / choses, c'est le monde intérieur du poète, ou [...] c'est / le monde des choses réfracté dans la conscience du poète, <c'est à / dire une expérience $>$ "

12 Todas as traduçôes que seguem foram feitas por mim e terão os originais apresentados em nota de rodapé.

${ }^{13}$ No original: "les aspirations, les / délires, les souvenires dans le / style qui convient à l'exté-/ riorité".

${ }^{14}$ No original: " monde / second" , "monde de la / sensibilité pris en lui-même", "monde du rêve et de la nostalgie".

${ }^{15}$ No original: "du rêve, a des couleurs oniriques".
} 
essa discussão sobre a poesia de Baudelaire vai aproximando a discussão de Benveniste sobre a linguagem poética à ideia de que ali estaria em jogo esse mundo interior do poeta. Ora, esse mundo interior significa também o delírio, o sonho, conforme o vemos teorizando no PGL I. Em seguida, Benveniste (2011, p. 426) lança mão de uma nota, que auxilia também na elucidação dessa questão, "Ver no Salão de 1859 (Clube do livro II p. 143) a página onde Baudelaire elogia Delacroix / por ter 'o infinito no finito' ... o sonho... a visão produzida pela intensa / meditação... E. D. pinta sobretudo a alma ... [...] Jamais esquece 'a rainha / das faculdades', a imaginaçáo". ${ }^{16}$

A discussão proposta em Benveniste (2005b) que, conforme pontuei, também se encontra em Benveniste (2011), encontra eco no texto "Semiologia da língua". Neste texto, a discussão sobre a poesia que se constrói a partir de um mundo interior, o mundo do poeta, que alcança também seus sonhos, seus devaneios e suas aspiraçóes, pode ser ainda compreendida a partir do que Benveniste (2006b) discute especificamente sobre a arte.

"Semiologia da língua" foi publicado originalmente em 1969. Nele, como observam Meschonnic (2008b) e Dessons (1997), Benveniste inicia uma discussão que será importante para pensar a arte e a linguagem poética. $\mathrm{Na}$ tentativa de definir o que é próprio da língua, comparando-a à arte, Benveniste (2006b) propóe que a língua é o único sistema de significação a ter a propriedade de congregar de uma só vez o domínio semiótico e o domínio semântico, ou seja, o sistema de signos e o discurso. Assim, os outros sistemas ou são constituídos apenas pelo semiótico, gestos de cortesia, mudrās, ou são constituídos apenas pelo semântico, como as expressóes artísticas.

Conforme Meschonnic (2008b), Benveniste, nesse texto, faz uma dissociação entre a noção de signo e de unidade. Em "Semiologia da língua", o signo apresenta-se como uma unidade, no entanto, uma unidade náo seria necessariamente um signo. É possível, portanto, considerar, por exemplo, as obras de arte enquanto unidades produtoras de sentido, que não podem ter seus elementos discretizados, já que não são constituídas de unidades que teriam um valor dado previamente.

A reflexão proposta tanto por Meschonnic (2008b) quanto por

\footnotetext{
16No original: "Voir dans le Salon de 1859 (Club du livre II p. 143) la page où Baudelaire loue Delacroix / d'avoir 'l'infini dans le fini', ... le rêve... la vision produite par une intense / méditation.... E. D. peint surtout l'âme... [...] Ne jamais oublier 'la reine / des facultés', l'imagination".
} 
Dessons $(1997)^{17}$, a partir do texto "Semiologia da língua", aponta para uma nova metodologia de trabalho. Enquanto, nos estudos da linguagem, geralmente se partiu de análises em que se consideravam unidades carregadas de sentido, que poderia ser alterado, segundo as novas relaçóes estabelecidas no discurso, os estudos de outros sistemas, aqueles de expressão artística, apontavam, em Benveniste (2006b), para que se considerasse a obra como um todo que atribuiria relação às partes. Pode-se, dessa forma, dizer que se trata de uma consideração da obra, a partir do que foi denominado "semântico sem semiótico", em que a obra cria seu próprio semiótico.

Ao considerar o estudo da linguagem poética, Meschonnic (2009) propóe que se considere o poema como uma obra de linguagem. Dessa forma, o teórico da linguagem considera, em suas análises, o poema como uma obra de arte, como aquele que constrói o seu próprio semiótico, a partir do domínio do semântico.

Em Benveniste (2011), ao analisar os poemas de Baudelaire, o linguista, em um primeiro momento, percebe algo interessante: "a linguagem icônica não rompe com o sistema geral / da língua, ela não emprega elementos fônicos nem signi/fqques que sejam estrangeiros à língua, e Baudelaire / conserva uma sintaxe que é no conjunto aquela / da língua comum"18 (p. 34, grifos meus). No entanto, parece que a organização desse sistema, tomado como "um sistema próprio", "agenciado segundo suas / próprias categorias e funçóes” (p. 48), torna essa linguagem uma "linguagem especial”, que não é mais a "linguagem ordinária embora formada das mesmas unidades"19 (p. 48).

Ao seguir com as análises e reflexôes, Benveniste explica que "O poeta combina e / <distribui> sua matéria como o / músico seus sons e o / pintor suas cores mas / diferentemente do pintor / e do músico que / empregam os materiais, / o poeta emprega as / palavras, que significam. / A poesia é portanto / algo contraditório : / uma arte de signi-/ficaçôes." ${ }^{20}$. Ao final de sua

17 É importante observar que essa discussão perpassa a obra de Henri Meschonnic e Gérard Dessons. Faço menção a esses textos especificamente, neste momento, porque auxiliarão mais diretamente na reflexão conduzida aqui.

${ }^{18}$ No original: "Le langage iconique ne rompt pas avec le système général / de la langue, il n’emploie pas d'elements phoniques ni signi-/fiques qui soient étrangers à la langue, et Baudelaire / conserve une syntaxe qui est dans l'ensemble celle de / la langue commune".

${ }^{19}$ No original: "un système propre"; "agencé selon ses / propres catégories et fonctions"; "langage spécial"; "le langage ordinaire quoique formé des mêmes unités".

${ }^{20}$ No original: "Le poète combine et / <distribue> sa matière comme le / musicien ses sons et le / peintre ses couleurs mais / à la différence du peintre / et du musicien qui / emploient 
reflexão, o linguista conclui que "seria bastante natural que a língua / poética tivesse sua semântica própria”"21.

Em outro momento do dossiê, Benveniste (2011, p. 652) nos faz lembrar da discussão do texto "Semiologia da língua", mas agora buscando explicar a língua, utilizando-se de características que observou sobre o sistema da arte e da música:

[...] As cores, a matéria, os sons são os materiais / de artistas pintores, escultores, músicos.

E o poeta? O poeta combina as palavras. As palavras / são o material sobre o qual ele trabalha. É por conseguinte / evidente que, tornadas material do poeta, as palavras não / podem mais ser "signos" do uso comum. / Cada poeta utiliza à sua maneira esse material. / Não há dois que tirem delas o mesmo partido.

Mas o pintor, com o auxílio de suas cores, faz um / quadro; o escultor, com sua matéria, faz uma / escultura; o músico, com os sons, faz uma / composição musical.

E o poeta? O poeta, com suas palavras, faz / um "poema", uma criação que explora as palavras / para certos fins. estéticos. ${ }^{22}$

Nesse recorte, é interessante observar que o poema é concebido como a arte da linguagem, que precisa ser explicado, via movimentos e reflexóes que, em Benveniste (2006b), se utilizou para discutir sobre o sistema da arte e da música. Chama, ainda, a atenção que o linguista aponta para o fato de os "signos" não serem mais aqueles do uso comum. Essa constatação se estabelece a partir da consideração de que náo haveria dois poetas que tirassem de uma mesma palavra dois usos comuns. O que estaria sugerindo Benveniste aqui? Trata-se de uma construção de um semiótico próprio?

des matières, / le poète emploie des / mots, qui signifient. / La poésie est donc / qqchose de contradictoire : / un art de signi-/fications."

${ }^{21}$ No original: "il serait assez naturel que la langue / poétique eût sa sémantique propre”.

${ }^{22}$ No original: "[...] Les couleurs, la matière, les sons sont des matériaux / des artistes peintre, sculpteur, musicien.

Et le poète? Le poète combine des mots. Les mots / sont le matériau sur lequel il travaille. Il est dès lors / évident que, devenus matériau du poète, les mots ne / peuvent plus être les "signes" de l'usage commun. / Chaque poète utilise à sa manière ce matériau. Il / n'y en a pas deux qui en tirent le même parti.

Mais le peintre, à l'aide de ses couleurs, fait un / tableau ; le sculpteur, avec sa matière, fait une / sculpture ; le musicien, avec les sons, fait une / composition musicale.

Et le poète ? Le poète, avec ses mots, fait / un "poème", une création qui exploite les mots / à certaines fins. esthétiques." 
Anteriormente, o linguista já fez a associação entre o poema e a arte, ao afirmar que nos poemas de Baudelaire trata-se de um semântico próprio. Estaria aqui propondo que o poema leva à construção de um semiótico próprio?

É mister também apontar, nessa nota, para a fato de que, ao mencionar a finalidade para a qual o poeta criaria o poema, extrapolando as palavras, Benveniste escreve a palavra "estético" e, em seguida, recua, rasurando-a. Podemos ler essa rasura, considerando toda a exposição das análises de Benveniste, as quais mostram, com agudeza, o quanto a forma como se organiza a língua nos textos analisados também constrói não apenas um universo do poeta, que refrata o mundo que o cerca, bem como um universo poético, no sentido de propor uma renovação na forma de pensar a poesia. Logo, o fim da criação que explora o uso das palavras não é apenas estético ${ }^{23}$.

Nessa nota, é de se observar o tato para uma análise linguística aguçada, que perpassa a obra de Benveniste. O linguista, ao considerar as relaçóes entre a forma e o sentido, mostra ter consciência de que, adentrar o segundo domínio, o leva a considerar a relação da língua, nesse caso específico, com a literatura. Ao fazê-lo, deixa-se interrogar, demonstra estar diante de um problema. É esse movimento que faz de Benveniste, conforme já apontei acima, um linguista único.

Debruçando-se sobre o literário, sem desconsiderar as especificidades da literatura, esse linguista, numa atitude daquele que busca deixar-se interrogar pela "terra incognitae" (terras desconhecidas), acaba por observar, de forma bastante instigante, que "a língua poética é sempre aquela de um poeta, e ela é / reinventada por ele em cada um de seus poemas"24 (p. 442); "A / poesia, é a poesia / mais um certo poeta. / porque cada poeta tem / sua língua poética." ${ }^{25}$ (p. 454).

\section{O encontro da poética de Benveniste com a poética de Meschonnic}

Embora esta seção do artigo seja dedicada à discussão acerca

\footnotetext{
${ }^{23}$ Agradeço a um dos pareceristas do periódico que atentou para o fato de que essa rasura também indica que o procedimento destacado por Benveniste também pode ser levado para o uso comum da linguagem, já que também se detectam aí procedimentos semelhantes.

${ }^{24}$ No original: "La langue poétique est toujours celle d'un poète, et elle est / réinventée par lui dans chacun de ses poèmes."

${ }^{25}$ No original: "La / poésie, c'est la poésie / plus un certain poète. / puisque chaque poète a / sa langue poétique”.
} 
do encontro das poéticas de Benveniste e Meschonnic, uma primeira aproximação já se estabeleceu na seção anterior, na medida em que a leitura do texto "Semiologia a língua" foi apresentada, a partir daquela feita por Meschonnic (2008b) e Dessons (1997). Foi possível observar que a leitura proposta pelos dois teóricos da linguagem, qual seja, aquela que considera a reflexão de Benveniste no "Semiologia da língua" sobre as expressóes artísticas como profícua para pensar a arte da linguagem, o poema, é o caminho percorrido por Benveniste (2011).

Ao discutir sobre o que denominou "linguagem poética", Benveniste (2011) observou que o poeta se comporta diante da língua tal como o pintor diante da sua obra, como o músico diante de sua composição. O linguista chega a afirmar que o "signo" de que lança mão o poeta não é o mesmo "signo" de que lança mão o falante comum.

Interessa aqui observar que, considerando a reflexão em Benveniste (2006b), Meschonnic (2008b) se propóe a fazer a metassemântica sugerida no final programático de "Semiologia da língua". Para fazê-lo, Meschonnic postula que sua poética se estabeleça, a partir do que denominou "semântico sem semiótico". Dessa forma, a obra e o poema são tomados como aqueles que constroem o seu próprio semântico, mas também o seu próprio semiótico. Tal consideração altera o ponto de vista do analista que não busca mais o funcionamento das unidades do semiótico no semântico, mas como o semântico constrói as unidades que se estabelecem como seu semiótico.

O olhar se volta para o contínuo do discurso, que é tomado por Meschonnic (2009) como um sistema, resgatando a reflexão saussuriana, por meio da oposição ao fechamento estruturalista. No entanto, esse sistema não é fechado. Trata-se de um sistema aberto, cujas relaçóes estabelecidas pelo funcionamento dos elementos que o compóem sempre estáo abertas a novas possibilidade de escuta e de leitura. Escuta aqui se relaciona à leitura, na medida em que as relaçóes se organizam a partir do ritmo ${ }^{26}$, que não é mais concebido como simétrico, regular, mas como "configuraçôes particulares do movimento" (MESCHONNIC, 2009, p. 70, apud BENVENISTE, 1966, p. 330).

Esse ritmo, alçado a um verdadeiro interpretante antropológico, conforme o pontua Dessons (2006), não se trata mais de um nível. O ritmo funciona como um organizador das relaçóes que se estabelecem no discurso e que se situam nos níveis acentual, prosódico, morfológico, sintático e lexical. Esse sistema de discurso constrói, dessa forma, sua própria sintagmática e

26Para maiores informaçôes sobre a noção de ritmo, consultar Meschonnic (2009). 
sua própria paradigmática ${ }^{27}$. É a partir das relaçôes entre tais eixos, que se estabelece a significância do sistema e da obra.

A organizaçáo do movimento do discurso, sendo constituída pelo ritmo da linguagem, leva à consideração da escuta do texto, na atividade de análise. Essa possibilidade se estabelece, na medida em que não se desvinculam, na poética de Meschonnic, a forma e o sentido, o som e o sentido. Tal questão pode ser considerada uma primeira aproximação, dentre aquelas que busco estabelecer nesta seção, na medida em que, a partir das análises dos poemas de Baudelaire, Benveniste (2011) afirma que "1) a dicotomia forma : sentido / tem aqui ainda menos sentido que em qualquer outro lugar. / 2) o 'sentido' em poesia é interior à 'forma"”28 (p. 548); “Em poesia a distinção entre a forma e o fundo (supondo que ela / tenha em si um sentido) é abolida. O 'fundo' da poesia é a sua 'forma'”29 (p. 428).

A consideraçáo de que o poema e a obra constroem um sistema de discurso, cujas relaçóes se estabelecem internamente, parece estar bem presente em algumas observaçóes de Benveniste (2011) acerca dos poemas de Baudelaire, na media em que "não há signo isolado que, em si, possa ser considerado como / próprio à linguagem poética ou realizando o efeito poético / (exceto alguns clichês 'glaive' 'onde' 'azur') ${ }^{30 ”}$ (p. 428); “em poesia o conjunto prima e determina a unidade" ${ }^{11}$ (p. 428).

Ainda a questão das relações sintagmáticas e associativas, consideradas em Benveniste (2011), nos remetem a essa discussão acerca da organização do discurso, a partir de uma paradigmática e de uma sintagmática, conforme o propóe Meschonnic (2009). No dossiê Baudelaire, lemos: "o linguista tem, portanto, que estudar: $1^{\circ}$ ) o princípio dessa sintag-/mática particular. $\left.2^{\circ}\right)$ as relaçôes significantes assim obtidas"32.

Ademais "o princípio é que cada palavra poética tem seu / paradigma poético poemático; que é constituído / pelo conjunto de possibilidades de rima ${ }^{27}$ As noçôes de sintagmática e paradigmática também derivam do pensamento saussuriano, mais especificamente dos eixos sintagmático e associativo do sistema linguístico.

${ }^{28}$ No original: "1) la dichotomie forme : sens / a ici encore moins de sens que partout ailleurs. 12) le 'sens' en poésie est intérieur à la 'forme'".

${ }^{29}$ No original: "En poésie la distinction de la forme et du fond (à supposer qu'elle / ait en soi un sens) est abolie. Le 'fond' de la poésie, c'est sa 'forme”".

${ }^{30}$ No original: "Il n'y a pas de signe isolé qui, en soi, puisse être considéré comme / propre à la langue poétique ou réalisant l'effet poétique / (hormis quelques clichés 'glaive' 'onde' 'azur')”.

${ }^{31}$ No original: "En poésie l'ensemble prime et détermine l'unité".

${ }^{32}$ No original: "Le linguiste a donc à étudier : $1^{\circ}$ ) le principe de cette syntag-/matique particulière. $2^{\circ}$ ) les relations signifiantes ainsi obtenues". 
que a palavra em / questão comporta. Esse paradigma, nós o dizemos / poemático porque ele é exigido por essa estrutura. Ele / vale para a parte terminal do verso somente" ${ }^{33}$ (p. 662). Haverá também, paralelamente, "uma sintagmática / poemática a ser reconhecida: é aquela que é coman-/ dada teterminada pela medida do verso (interdição / de exceder um número dado de sílabas, divisóes / internas, etc.)"34 (p. 662).

Embora o eixo das associaçóes, para Meschonnic (2009), não se reduza a rimas externas, mas compreenda relaçôes estabelecidas através também de rimas internas e de ecos prosódicos, e o eixo sintagmático não seja determinado pelo metro, pela medida, mas sim pelo ritmo, pelo contínuo do discurso; interessante se faz notar como as observaçóes de Benveniste e Meschonnic, a partir da análise de poemas, acabaram por leválos a discussóes bastante semelhantes e profícuas, que apontam um caminho para os linguistas que se propóem a não se colocarem como surdos à função poética da linguagem, para utilizar os termos e Jakobson (1999).

Nesse eixo de associaçôes, denominado paradigmática por Meschonnic (2009), Benveniste (2011) também acaba por considerar essa escuta do literário ao propor que se observem as "sonoridades associativas de evocaçáa". O linguista atenta para o fato de que "as três palavras urne nocturne - taciturne / têm ressonâncias idênticas - sonoridade <vibrante> de sino - e elas enlaçam as relaçôes de evocação"35 (p. 266); e de que "a evocação é uma categoria essencial em Baudelaire e talvez/ em geral em poesia" ${ }^{36}$ (p. 266).

Nessa discussão é que Benveniste (2011, p. 134) percebe que "NUIT tomada como pathème ${ }^{37}$ / ícone será distinta de noite como / signo, ainda que o poeta o empregue assim como / tal ("dia e noite" = sem cessar) quando tem

\footnotetext{
${ }_{33}^{3}$ No original: "Le principe est que chaque mot poétique a son / paradigme poétique poématique; celui est constitué / par l'ensemble des possibilités de rime que le mot en / question comporte. Ce paradigme, nous le disons / poématique parce qu'il est exigé par cette structure. Il / vaut pour la partie terminale du vers seulement".

${ }^{34}$ No original: "une syntagmatique / poématique à reconnaitre : c'est celle qui est comman-/ dée déterminée par la mesure du vers (interdiction / d'excéder un nombre donné de syllabes, divisions / internes, etc.)".

${ }^{35}$ No original: "Les trois mots urne - nocturne - taciturne / ont des résonances identiques sonorité < vibrante> de cloche - et ils nouent / et prolongent des relations d'évocation".

${ }^{36}$ No original: "L'évocation est une catégorie capitale chez Baudelaire et peut être / en général en poésie".
}

${ }^{37}$ Unidade semântica do domínio passional. 
oportunidade / <e será cada vez particular. Por exemplo>”38, "<o iconisante> nuit será - paradoxalmente mas / de acordo com a verdade icônica distinta da verdade / significa - ligado ao iconisante luit (XCI luisant / como esses buracos onde a água dorme na nuit... e a rima / reluit) e o iconizado NUIT será entáo / uma extensão <onde reina> uma certa claridade distinta da/ quela diurna" 39 .

O que o linguista mostra nessa análise é que "se trata de estabelecer uma ligação conceitual entre as palavras que rimam"0 (BENVENISTE, 2011, p. 650), assim nessas relaçôes "essas palavras se seguem; se combinam e compóem / figuras novas." ${ }^{\circledR 1}$ (BENVENISTE, 2011, p. 622); "aqui vale a observação profunda / de Saussure sobre a consecutividade como princípio fundamental/ / (Anagramas de F. De. S. Merc. De Fr. 1964, p. 254)" ${ }^{42}$ (BENVENISTE, 2011, p. 622).

Ao considerar a relação entre a forma e o sentido, o som e o sentido, nesse eixo sintagmático e paradigmático do poema, percebendo que as rimas formam essa rede conceitual que contribui para a constituição dos valores das unidades, Benveniste (2011, p. 400), assim como Meschonnic (2009), percebe que "a poesia a língua poética e mais precisamente a poética / não consiste em dizer, mas em fazer. Ela persegue / um <a produção de um> certo efeito, emocional e estético. Para esse / fim são empregados meios linguísticos" ${ }^{\text {‘3 }}$.Resulta disso, então, que "serão utilizadas / algumas propriedades da linguagem, propriedades sonoras / e propriedades de sentido. É em função dessas / propriedades que o autor (o 'faiseur, poiètès') / escolherá e combinará os elementos linguísticos”“44 (BENVENISTE, 2011, p. 400).

${ }^{38}$ No original: "NUIT pris comme pathème / iconie sera distinct de nuit comme / signe, bien que le poète l'emploie aussi comme / telte ("jour et nuit" = sans cesse) à l'occasion / <et il sera chaque fois particulier. Par exemple>".

${ }^{39}$ No original: "<l'iconisant> nuit sera - paradoxalement mais / en accord avec la vérité iconique distincte de la vérité / signifique - lié à des l'iconisant luit (XCI luisant / comme ces trous où l'eau dort dans la nuit... et la rime / reluit) et l'iconisé NUIT sera alors / une étendue <où règne> d'une certaine clarté distincte de / celle diurne".

${ }^{40}$ No original: "<Il s'agit d'établir un lien conceptuel entre les mots qui riment>”.

${ }^{41}$ No original: "Ces mots se suivent ; ils se combinent et composent / des figures neuves".

${ }^{42}$ No original: "Ici vaut l'observation profonde / de Saussure sur la consécutivité comme principe fondamental / (Anagrammes de F. De S. Merc. De Fr. 1964, p. 254)”.

${ }^{43}$ No original: "La poésie la langue poétique et plus précisément la poétique / ne consiste pas à dire, mais à faire. Elle poursuit / un <la production d'un> certain effet, émotionnel et esthétique. A cette / fin sont employés des moyens linguistiques".

${ }^{44}$ No original: "Il en résulte que seules seront utilisées / certaines propriétés du langage, propriétés sonores / et propriétés de sens. C’est en fonction de ces / propriétés que l'auteur (le 


\section{Consideraçóes finais}

O dossiê Baudelaire constitui-se como uma importante publicação, a qual, por um lado, lança luzes ao trabalho de estudiosos que, percebendo que a obra de Benveniste suscitava questionamentos importantes para quem se debruça sobre o literário, puderam compreender quais outros caminhos foram trilhados por esse grande linguista. De outro lado, essa publicação permite adentrar um pouco mais no universo de Benveniste, que, fascinado pela questáo da significaçáo, deixou-se interrogar por diferentes domínios dos estudos da linguagem, o que o levou à busca pelo desconhecido na arte e na literatura.

Benveniste é, sem dúvida, um "linguista à parte", que elaborou um pensamento acerca da linguagem que se configura como uma verdadeira "arte de pensar", conforme o destacou Dessons (2006). E foi nessa inquietação pelo estudo da arte da linguagem, revelada, em especial, pelo dossiê Baudelaire, que a sua poética encontrou, de uma forma diferente, a poética de Meschonnic ${ }^{45}$, conforme destaquei neste artigo. Apontar esse encontro me parece bastante profícuo, na medida em que novos horizontes e novas interrogaçóes se abrem àqueles que se dedicam ao estudo da arte da linguagem. Espero que esta reflexão leve outros pesquisadores a apontar outras convergências entre os trabalhos desses dois estudiosos da linguagem, bem como outras possibilidades de questionamentos e interrogaçóes acerca do texto literário, decorrentes desses aqui apresentados.

\section{Referências}

ADAM, Jean-Michel; LAPLANTINE, Chloé (Org.). Les notes manuscrites de Benveniste sur la langue de Baudelaire. Revue de sémiolinguistique des textes et discours. França: Presses universitaires de France-Comté, 2012.

'faiseur, poiètès') / choisira et combinera les éléments linguistiques".

${ }^{45}$ É mister destacar que Meschonnic toma Benveniste como um dos autores de base para a construção de sua poética, juntamente com Saussure e Humboldt. Por isso, é comum que se relacione o pensamento desses dois grandes estudiosos da linguagem pensando na influência de Benveniste no pensamento de Meschonnic. No entanto, neste texto, pontuo esse encontro, em especial, a partir do Dossiê Baudelaire, cujas notas, embora tenham sido produzidas em finais da década de sessenta, somente vieram a público depois dos anos 2000. Ou seja, em torno de 27 anos após a publicação de Critique du rythme, obra que fundamenta muitos dos debates levantados aqui. 
BÉDOURET-LARRABURU, Sandrine; LAPLANTINE, Chloé (Org.). Émile Benveniste: vers une poétique générale. França: Presses de l'Université de Pau et des Pays de l'Adour, 2015.

BENVENISTE, Émile. A forma e o sentido na linguagem. In:

Problemas de lingüística geral II. Campinas: Pontes, 2006a.

. Semiologia da língua. In: . Problemas de lingüística geral II. Campinas: Pontes, 2006b.

. Os níveis de análise linguística. In: Problemas de lingüística geral I. Campinas: Pontes, 2005a.

. Observaçôes da função da linguagem na descoberta freudiana. In: . Problemas de lingüística geral I. Campinas: Pontes, 2005b.

. Baudelaire. França: Limoges, Éditions Lambert-Lucas, 2011.

DESSONS, Gérard. Pour une sémantique de l'art. In: NORMAND, Claudine; ARRIVÉ, Michel. Émile Benveniste vingt ans après. Numéro Spécial de LINX. Nanterre, 1997.

. Émile Benveniste, l'invention du discours. Paris: Press, 2006.

. Le poème. Paris : Armand Colin, 2011.

; NEUMANN, Daiane; OLIVEIRA, Giovane F. Émile Benveniste e a arte de pensar: uma entrevista com Gérard Dessons. REVEL, vol. 18, n. 34, 2020. Tradução de Daiane Neumann e Giovane Fernandes de Oliveira. FLORES, V. do N.; LAPLANTINE, C.; TEIXEIRA, M. Émile Benveniste: em direção a uma poética do discurso. In: Caleidoscópio. Vol. 11., n. 2, maio/agosto de 2013.

JAKOBSON, Roman. Lingüística e poética. In: . Linguística $\mathrm{e}$ comunicacáo. São Paulo: Editora Cultrix, 1999.

MARTIN, Serge. Émile Benveniste pour vivre langage. França: L'atelier du Grand Tétras, 2009.

MESCHONNIC, Henri. Seul comme Benveniste. In: Dans le bois de la langue. Paris: Editions Laurence Teper, 2008a.

. Benveniste: sémantique sans sémiotique. In: Dans le bois de la langue. Paris: Editions Laurence Teper, 2008b.

. Critique du rythme: antropologie historique du language. Lonrai, França: Éditions Verdier, 2009. 
MESSA, Rosângela M.; TEIXEIRA, Marlene. Émile Benveniste: uma semântica do homem que fala. Revista Estudos da Língua(gem), Vitória da Conquista, v. 13, n. 1, p. 97-116, 2015.

VIER, Sabrina. Émile Benveniste e a literatura. Revel, edição especial, n. 11, p. 70-83, 2016. 